\title{
DIREITOS HUMANOS, CIDADANIA E CRIMES DE ÓDIO: UM ENSAIO SOBRE O PROBLEMA NA EUROPA CONTEMPORÂNEA
}

\section{HUMAN RIGHTS, CITIZENSHIP AND HATE CRIMES: AN ESSAY ON THE ISSUE IN CONTEMPORARY EUROPE}

DOI: http://dx.doi.org/10.15448/2178-3748.2016.1.22906

\author{
Tatiana Poggi \\ Professora de História Contemporânea - UFF \\ tatiana.poggi@gmail.com
}

\begin{abstract}
RESUMO: O artigo pretende relacionar o problema do aumento da violência motivada pelo ódio com o debate sobre os direitos humanos e sociais. Iniciaremos apresentando rapidamente o debate sobre os direitos humanos, parte do processo histórico de conquistas de direitos civis, políticos e sociais. Seguiremos então com a discussão sobre crimes de ódio na Europa Ocidental.
\end{abstract}

PALAVRAS-CHAVE: Crimes de ódio. Violência. Direitos Humanos.

ABSTRACT: The article intends to bring forward the matter of hate crimes establishing a connection with the debate on human and social rights. We begin by presenting the development of human rights, part of a historical process of achievements on civil, political and social rights. The debate on hate crimes in Western Europe follows, discussing the main issues highlighted by researchers in the field.

KEYWORDS: Hate crimes. Violence. Human Rights.

\section{Introdução}

A reflexão proposta nesse artigo vem recuperar o processo histórico de conquista de direitos e constituição da cidadania, observando como nos últimos 30 ou 40 anos esses mesmos direitos vêm sendo continuamente atacados e ameaçados. O crescimento e a naturalização da violência motivada pelo ódio e pela intolerância mostra que mesmo o direito mais básico - o direito à vida e à integridade física - conquistado nos auspícios do liberalismo está em xeque.

O direito à vida encontra-se sob ameaça não exatamente pela ação de indivíduos ou grupos uns contra os outros. Sabemos que essas manifestações acompanham nossa história, mesmo após a conquista de um conjunto de direitos e da ampliação da cidadania. Nesse sentido, a vida em si - não o direito a ela - sempre esteve sob ameaça. O direito à vida encontra-se ameaçado quando o poder público e a esfera internacional encontram dificuldades em se posicionar legal e enfaticamente sobre a violência motivada pelo ódio, fechando os olhos para ela, se esquivando da questão através de explicações como "casos isolados" perpetrados por indivíduos mental e psiquicamente perturbados, ou seja, não combatendo-a 
abertamente como um problema social. Enfim, o problema se coloca quando o poder público se esquiva de uma de suas obrigações fundamentais e fundacionais: salvaguardar a vida de seus cidadãos. A salvaguarda da vida, juntamente com a defesa da propriedade privada, são os dois pilares fundamentais do contrato social no nascimento do liberalismo; são os primeiros direitos conquistados pelos homens segundo a tradição política ocidental; são o capítulo inicial e mais elementar da história da cidadania, posto que sem a salvaguarda da vida como direito assegurado não há como reclamar e conquistar direito algum. A tradição contratualista e jusnaturalista imprime uma lógica racional na relação Estado-indivíduo, apresentando o Estado e, em decorrência, o próprio processo de sociabilização como uma criação racional dos indivíduos, rompendo por definitivo com o modelo organicista aristotélico. O contrato, ação racional orientada a um fim, funda o Estado e a sociedade civil, coroando o indivíduo como grande artífice das instituições e relações políticas, não mais submetido a uma lógica de poder de fundo teológico ou natural. Suas ações e pressões abrem caminho para as lutas em defesa da liberdade, de direitos individuais, civis, e posteriormente tantos outros direitos, limitando o poder do Estado. Surge assim, especialmente a partir de Locke, a ideia do Estado de direito e do contrato como pacto consentido (MONDAINI, 2015, p. 128-130).

O fato deste direito primo estar sob ameaça é um perigo fulcral não apenas para democracia, mas para a própria ideia de cidadania e de organização política e social de base contratualista. Contudo, como veremos a seguir, são os próprios limites da democracia liberal, expressos pelos ataques aos direitos políticos e sociais dos cidadãos, pelo descaso quanto à violação dos direitos humanos de alguns e pela negação ao exercício pleno da cidadania que nos impedem de superar essa contradição.

\section{A longa e tortuosa estrada da conquista dos direitos}

A história da luta pela conquista de direitos e cidadania vem se mostrando um caminho longo e tortuoso; as situações, espinhosas; os desafios, incontáveis. Mas diferente dos romances, essa história não tem final definido, as batalhas não cessam e o caminho segue sem garantias, nem mesmo de manutenção daquilo que já foi conquistado ao longo da longa e tortuosa estrada. No correr da história, indivíduos, detentores apenas do fato de serem humanos, tornaram-se, através de intensas lutas, cidadãos, detentores de direitos civis, políticos, sociais e humanos. Atualmente, muitos desses direitos se veem ameaçados por uma democracia socialmente excludente, atomizante, alienante e muitas vezes complacente com a violência motivada pelo ódio. 
Esse é um primeiro aspecto a ser ressaltado. Os caminhos da história não levam a um lugar definido. Há diversas estradas, que dependem de projetos em disputa e da correlação de forças em determinados momentos e espaços históricos. Há, portanto, uma multiplicidade de possibilidades e a história da cidadania não consiste em um desenvolvimento de tipo evolutivo, num processo teleológico em direção ao progresso, ao bem viver e à uma sociedade harmoniosa. É certo que podemos traçar um histórico dessas conquistas, mas essa é uma história particular e distinta entre nas nações com avanços e reveses; vitórias e derrotas; negociações, barganhas e retrocessos. Direitos civis, políticos, trabalhistas, sociais e humanos podem ter surgido historicamente no horizonte das lutas sociais nessa ordem, todavia não foram bandeiras defendidas ou conquistadas consecutivamente em todas as sociedades, não podendo ser entendidos como consequentes ou desencadeadores uns dos outros. Casos como o dos EUA e da África do Sul são emblemáticos, haja vista que até os anos 1960 e 1990 respectivamente o segregacionismo era tolerado e diretos civis e políticos básicos não estavam assegurados para uma parte da população. Grandes ONGs internacionais como Anistia Internacional, Human Rights Watch e International Commission of Justice defendem direitos humanos sem tocar necessariamente na questão dos direitos políticos, sociais ou trabalhistas (CMIEL, 2004, p.130). Essas lutas aparecem dissociadas, podendo-se inclusive questionar a amplitude e o sentido de uma luta em prol da integridade e dignidade humana que não leve em consideração as condições econômicas e sociais às quais estão submetidos os indivíduos. A subalternização e a produção social e mundial da probreza não agrediriam e comprometeriam também a integridade e a dignidade humana? Como, então, pensar direitos humanos dissociados de direitos sociais?

Ainda assim, as abordagens de cunho linear e idealista do processo predominam entre as análises, podendo ser vistas desde o estudo clássico de T. H. Marshall (1967), como mais recentemente no debate sobre direitos humanos através dos trabalhos de Karal Vasak (1978), Lynn Hunt (2009), Paul Lauren (2003) e Micheline Ishay (2004). O tom demasiado otimista, quase épico dessas narrativas, se assemelha a uma saga, uma história na qual a penúrias e adversidades fazem sentido justamente por levarem a um lugar melhor, a um mundo melhor. Nesses trabalhos é produzida uma narrativa histórica, baseada na dinâmica do "efeito dominó", um processo irresistível de constante alargamento e aprofundamento de direitos. Superação, vitórias e progresso constante, ainda que gradual, são elementos marcantes nessas análises. E ainda que o presente seja um ambiente social que apresente uma série de desafios, a ideia passada é que ao menos estamos a olhar para o problema como um problema, as violações de direitos humanos chamam atenção, leis internacionais estão se expandindo,

Oficina do Historiador, Porto Alegre, EDIPUCRS, v. 9, n. 1, jan./jun. 2016, 
ditadores podem ser processados, ou seja, uma narrativa que reforça o sentido teleológico da abordagem e a ideia de progresso constante em direção a dias melhores.

Em 1950, o sociólogo britânico T.H. Marshall publicou um conjunto de ensaios sob o título "Cidadania, classe social e status" que se tornou uma referência para o debate de cidadania. Marshall desenvolveu um conceito de cidadania ancorado em três elementos básicos - civil, político e social - frutos do processo social e histórico de conquista gradativa de direitos. Seu trabalho procura construir uma periodização que explicite as lutas em torno da conquista e o aprofundamento da cidadania conforme a interação e complementação desses direitos, de forma que o pleno exercício da cidadania exigiria o acesso de todos a um conjunto direitos (MARSHALL, 1967, p.84).

Os direitos de primeira e segunda geração - civis e políticos - datam da formação do Estado moderno, do estabelecimento do paradigma contratual e do desenvolvimento do capitalismo liberal, garantindo, por meio da lei, igualdade civil, direito de propriedade, liberdade de expressão e participação política. Segundo Marshall, a igualdade civil auxiliou o desenvolvimento do capitalismo, pois com ela ficou garantido o direito de buscar possuir, o direito de acesso ao mercado e o direito à justiça. Contudo, todos esses direitos tornam-se vazios quando faltam meios aos indivíduos, isto é, meios de adquirir bens e mercadorias, meios de acesso à justiça, meios de se fazer ouvido, meios de elaborar um pensamento crítico, etc. Quando os indivíduos não têm condições mínimas, eles estão consequentemente privados dos instrumentos para exercer a cidadania, para usufruir e exercitar seus direitos (MARSHALL, 1967, p.80-83). A busca de meios pelo gozo dos direitos civis e políticos conduzira, conforme sua narrativa, à novas reivindicações e lutas que teriam aberto caminho para novos direitos - os sociais - possibilitando o pleno exercício dos primeiros (MARSHALL, 1967, p.93).

A conquista de direitos sociais, bem como dos direitos políticos, imprime ainda uma mudança de ideias quanto à função do Estado, tido não somente como representante de todos e garantidor de direitos, mas também responsável pelas condições de vida e bem-estar (MARSHALL, 1967, p.85-88). Recuperando a perspectiva socialdemocrata clássica, Marshall chega a perceber um potencial ameaçador desses direitos ao capital, uma vez que o compromisso do Estado com o bem comum seria cobrado não mais somente através do contrato, mas principalmente através da militância e do poder de ingerência e governo das classes subalternas. Assim, pode-se notar a linearidade da abordagem de Marshall, bem como a dinâmica de "efeito dominó" que marca o encadeamento entre as gerações de conquista de direitos. 
O debate em torno da origem dos direitos humanos foi fortemente marcado por essa perspectiva linear e evolutiva. Boa parte dos estudos faz alusão a pensadores Iluministas e à discussões muito em voga no século XVIII sobre os direitos naturais, sobre a "necessidade" de um contrato social e sobre o papel ativo do Estado em garantir por meio constitucional esses direitos, que exatamente por serem naturais, seriam inalienáveis e universais. A fundação do Estado moderno e a conquista dos primeiros direitos são tidos como pontos de partida de um longo processo de defesa dos direitos humanos.

O trabalho de Karal Vasak (1978) é paradigmático, demonstrando forte semelhança temporal e substancial com o esquema proposto por Marshall. Ele aponta a origem dos direitos humanos no contexto do Iluminismo, conformando uma primeira geração responsável pelo avanço nas dimensões civil e política, e segue afirmando um aprofundamento do processo em duas gerações subsequentes, marcado por avanços nas esferas econômico-social (no pós-segunda guerra) e pela autodeterminação/solidariedade (com a descolonização).

Lynn Hunt (2009) também inicia seu exercício de busca pelas origens dos direitos humanos no século XVIII, porém sua grande contribuição está em entender os direitos humanos como compostos de elementos de razão e emoção, ou seja, para ela os sentimentos esclarecidos - a capacidade de empatia entre os seres humanos, de reconhecer o outro como semelhante, merecedor de respeito e senhor de si assim como eu - importam mais que os ideais esclarecidos (HUNT, 2009, p. 25-28). É esse sentimento que possibilita o ideal de universalidade impresso na Declaração de Independência dos EUA, na Declaração dos Direitos do Homem e do Cidadão de 1789 e na Declaração Universal do Direitos Humanos da ONU de 1948. Além disso, o pressuposto da universalidade ostentado nesses documentos estimulou outros povos, minorias e grupos subalternos a exigir direitos. As lutas em torno de direitos políticos, sociais, das mulheres, de libertação nacional e sexual, pelo fim da segregação, em prol da tolerância religiosa, foram todas alimentadas pelos pressupostos da primeira conquista: igualdade civil e universalidade.

Perspectiva similar é trazida por Lauren (2003), que faz um trabalho primoroso de resgate da história do ativismo em torno dos direitos humanos, sendo o primeiro a debater de forma densa a questão racial e o impacto do imperialismo no desenvolvimento dos direitos humanos. Segundo ele, o vocabulário político de defesa de direitos humanos foi reapropriado e utilizado nas lutas dos afro-americanos durante o movimento em prol dos direitos civis nos EUA, pelos sulafricanos em sua luta contra o Apartheid e por diversos ativistas nacionalistas na Ásia e na África durante as guerras de independência. Assim, os direitos humanos progrediram em resposta às violações em si, observando, portanto, um progresso contínuo das

Oficina do Historiador, Porto Alegre, EDIPUCRS, v. 9, n. 1, jan./jun. 2016, 
discussões, acordos e diretrizes internacionais, no sentido de definir, regulamentar e proteger a integridade e a dignidade humana. Sua história dos diretos humanos traz contribuições inovadoras, contudo, a abordagem linear acaba por glorificar o presente, reforçando a narrativa épica, especialmente por se concentrar no papel dos movimentos sociais. Além disso, a análise das lutas dá vida, carne e osso aos ideais, aumentando sensivelmente a sensação de vitória e progresso se comparado a um estudo sobre história das ideias.

Ainda dentro do escopo das abordagens lineares, a proposta mais radical de análise parece vir de Micheline Ishay (2004). A socióloga israelense constrói uma análise transhistórica dos direitos humanos, entendendo-os como universais, naturais e onipresentes. Para a autora, direitos humanos sempre estiveram no horizonte da humanidade e ao longo dos séculos pensadores de tradições políticas variadas debateram mais sobre seus componentes do que seu conteúdo propriamente dito, elencando quais elementos deveriam ressaltados, quais bandeiras deveriam assumir lugar de destaque. Ao eternizar os direitos humanos, Ishay radicaliza a narrativa linear e idealista.

A perspectiva linear, apesar de ainda hoje bastante popular, apresenta controvérsias no tocante à forma como entende a história, o processo de luta por direitos e a experiência da cidadania. Pendas (2012, p.100) e Cmiel (2004, p.126-127) destacam que tais autores perdem de vista o fato de que esses direitos até Declaração Universal dos Direitos Humanos da ONU foram assegurados, exercidos e respeitados dentro dos limites do Estado Nacional, ou seja, seriam direitos universais garantidos pelo Estado Nacional, instituição realmente soberana no sistema internacional, consistindo, portanto, muito mais em direitos individuais, civis, que humanos. E mesmo após a criação da ONU e da Declaração de 1948, o que se tem é um conjunto de leis internacionais com poder muito mais sugestivo que deliberativo.

Como aponta Cmiel (2004, p.130-131), o vocábulo "direitos humanos" e o conjunto de ideais e pautas associados a eles só passaram a ser invocados e reivindicados após a década de 1940. Não havia anteriormente movimentos sociais ou ONGs falando em nome dos direitos humanos e lutando por esses princípios; não havia até a Declaração Universal da ONU nenhum acordo ou lei internacional voltados para proteção de direitos humanos. A partir dos anos 1980 e 1990 observa-se um aumento significativo do ativismo em favor dos direitos humanos, bem como um alargamento da agenda, abraçando causas como o direito das mulheres, das crianças e, em alguns casos, o entendimento dos direitos sociais (saúde, educação, habitação, cultura...) como direitos humanos. Contudo, o autor pondera sobre o impacto político e social e sobre a capacidade de uma real transformação social gerada pelo fortalecimento dos debates e pelo aumento de ONGs em defesa dos direitos humanos. O cerne 
de sua ponderação não está obviamente em criticar a luta por direitos humanos, mas sobre os resultados práticos, sociais e materiais da ação política impulsionada por essas lutas.

Sua crítica é construída com base nas conclusões de alguns ativistas, jornalistas e acadêmicos um tanto céticos quanto às reais conquistas da luta por direitos humanos. $\mathrm{O}$ professor e escritor Adam Hochschild (1998) e a jornalista e diplomata Samantha Power (2002), além de pesquisadores dos direitos humanos, participaram de importantes movimentos sociais e militam em organizações de defesa de direitos humanos. ${ }^{1}$

O livro de Hochschild (1998) consiste em uma feroz e aberta crítica à colonização do Congo Belga e à particular atuação do rei Leopoldo II como condutor de uma política colonial violenta, cruel e corrupta, porém reconhecida e aceita internacionalmente. Ao longo do livro, o autor procura demonstrar através da análise documentos históricos e do mapeamento de variadas declarações sobre as atrocidades no Congo Belga como, apesar de conhecida, uma realidade atroz era abertamente tolerada pela comunidade internacional.

O argumento Power (2002) segue em linha parecida. A autora desenvolve um estudo sobre a postura dos EUA frente aos casos de genocídio e limpeza étnica experimentados desde o massacre armênio de 1915, passando pelo Holocausto e chegando até a guerra do Kosovo em 1998. Em suas análises, ela observa uma constante relutância de figuras públicas e políticos norte-americanos em condenar publicamente violações de direitos humanos, muitas vezes evitando o uso da palavra genocídio.

As críticas de Hochschild e Power lançam um polêmico e delicado debate sobre o impacto da indiferença diante de atrocidades. Indagam sobre o poder e o direito de ingerência de um Estado sobre os outros e questionam até que ponto deveríamos nos relacionar com a barbárie com base no respeito ao relativismo cultural ou na não intromissão em questões nacionais. Tal avaliação sobre os direitos humanos nos leva a refletir sobre a garantia, o respeito e o exercício de outros direitos no mundo contemporâneo. Em que medida ser cidadão hoje significa usufruir e exercitar mais nossos direitos? Até que ponto o exercício da cidadania e a organização de uma comunidade cívica estão necessariamente atrelados e dependentes do Estado como formação política e de um arcabouço constitucional? Alguns pensadores vêm se debruçando sobre essa questão, problematizando o caráter, o conteúdo e o significado da cidadania e da democracia em nossos dias.

\footnotetext{
${ }^{1}$ Hochschild foi um ativista nas lutas contra o Apartheid, no movimento pacifista e pelos direitos civis nos EUA; Power foi conselheira no Departamento de Estado no governo Obama e diretora de direitos humanos e assuntos multilaterais no Conselho de Segurança Nacional entre 2008 e 2013, quando se tornou porta voz de importantes causas como os direitos das mulheres e LGBTs; proteção de minorias religiosas e refugiados; campanha contra tráfico humano.
} 
Ainda nos anos 1990, logo após a queda do muro de Berlim e a desagregação do "mundo socialista", Ellen Wood (2006) e Domenico Losurdo (2004) começaram a produzir importantes trabalhos sobre o caráter da democracia, investigando semelhanças e diferenças entre diferentes experiências democráticas, desde a Pólis grega até sua organização moderna em meio a conformação e desenvolvimento do capitalismo.

A discussão desenvolvida por Losurdo em "Democracia e Bonapartismo" (2004) parte da crítica de um mito muito difundido pelo liberalismo, no qual esse teria se transformado gradualmente em democracia; uma democracia cada vez mais ampla e próspera, possibilitada graças à defesa histórica do livre mercado. Nessa perspectiva, democracia se identifica com livre mercado e com sufrágio universal, sendo entendida mesmo como uma evolução do liberalismo, apagando todo um histórico de lutas da classe trabalhadora na conquista de direitos e da democracia em si.

Para se contrapor a tal narrativa, que ao fim confirma, fundamenta e justifica a própria democracia liberal, Losurdo se propõe a investigar a fundo a tradição liberal, demonstrando os entraves que essa forma de organização social impôs historicamente à democracia, à participação e à soberania popular. Ele parte da investigação de pensadores liberais clássicos como Burke, Sieyes, Constant, Mises, Hayek, Schumpeter, Popper e Bobbio, analisando como cada um deles via o sufrágio universal e a participação ativa das camadas populares como um perigo à ordem, uma atitude política irresponsável, na medida em que entendem esses setores como mal preparados para o viver político, incapazes de tomar decisões racionais, maduras e prudentes (LOSURDO, 2004, p.245-269). É inegável a contribuição do liberalismo para com a conquista da liberdade e igualdade civil e para com a própria ideia de direitos universais. Contudo, como pontua Vieira, o liberalismo

reduziu a cidadania a um mero status legal, estabelecendo os direitos que os indivíduos possuem contra o Estado. É irrelevante a forma do exercício desses direitos, desde que os indivíduos não violem a lei ou interfiram nos direitos dos outros. (...) Os ideais da "virtude republicana" são relíquias prémodernas e devem ser abandonadas. Para o liberalismo, a participação política é incompatível com a ideia moderna de liberdade. A liberdade individual só pode ser compreendida de forma negativa, como ausência de coerção (VIEIRA, 2001, p.71).

Para Losurdo, a democracia é uma conquista da classe trabalhadora e não se restringe ao sufrágio universal e aos direitos políticos, englobando também todo um conjunto de direitos sociais, que dotariam a cidadania de substância. Os direitos sociais remontam à Robespierre e seu entendimento de que a garantia da participação política e do direito à vida 
passava também pela garantia da subsistência, à revolução de 1848 e suas reivindicações por sufrágio e direito ao trabalho, à outubro de 1917 e ao princípio da emancipação total, chegando ao Estado de bem-estar social do pós guerra. Porém, todo esse histórico de lutas e conquistas se deu em meio ao capitalismo. A democracia burguesa, por mais inclusiva que seja, por mais aspectos sociais que apresente, é ainda uma democracia atravessada pela desigualdade, pela alienação, por desiguais oportunidades de acesso à cultura, à educação e aos meios difusão e propagação de ideais e projetos. Isso implica, segundo Losurdo, numa redução e redefinição drástica da ideia de democracia, comprometendo o ideal de emancipação e o nível de participação. O sentido do conceito de democracia proposto por Losurdo ultrapassa a dimensão civil e política, sendo profundamente social.

Wood (2006) aprofunda a discussão, colocando a democracia como grande desafio ao capitalismo. O capitalismo tem a capacidade de distribuir universalmente bens políticos sem colocar em risco as relações de exploração, a coerção e a desigualdade, posto que no capitalismo a cidadania não determina a posição econômica e o trabalhador, por sua vez, só pode desfrutar dos direitos à liberdade, igualdade jurídica e participação política no capitalismo conquanto não ameace o poder de apropriação do capital (WOOD, 2006, p.173). Nesse sentido, o primeiro aspecto apontado por Wood converge com Losurdo ao entender que a cidadania e a experiência democrática no capitalismo são limitados pela desigualdade.

...o capitalismo é, na essência, incompatível com a democracia. E é incompatível não apenas no caráter óbvio de que o capitalismo representa o governo de classe pelo capital, mas também no sentido de que o capitalismo limita o poder do "povo" entendido no estrito significado político. Não existe um capitalismo governado pelo poder popular, não há capitalismo em que a vontade do povo tenha precedência sobre os imperativos do lucro e da acumulação, não há capitalismo em que as exigências de maximização dos lucros não definam as condições mais básicas da vida (WOOD, 2006, p.8).

Wood destaca o caráter passivo da democracia liberal, se comparado à democracia ateniense ou mesmo ao republicanismo clássico. No republicanismo, ainda que a participação e a tomada de decisões políticas fossem permitidas apenas a um corpo civil limitado pela renda e pela propriedade - um grupo exclusivo de cidadãos -, percebe-se uma experiência dinâmica, com a participação ativa de seu pequeno núcleo governante. $\mathrm{O}$ atributo essencial a democracia moderna está em consistir num grupo abrangente de cidadãos passivos, uma coleção cada vez mais desagregada de cidadãos atomizados, isolados, muito diferente do demos ateniense ou da moderna ideia de poder popular, tidos como comunidade ativa de cidadãos. 
... a democracia capitalista ou liberal permitiria a extensão da cidadania mediante a restrição de seus poderes (como fizeram os romanos). Onde um propôs com corpo ativo, mas exclusivo, de cidadãos em que as classes proprietárias governariam a multidão trabalhadora, o outro foi capaz de imaginar um corpo abrangente, mas grandemente passivo, de cidadãos composto pela elite e e pela multidão, embora sua cidadania tivesse alcance limitado (WOOD, 2006, p.180).

Não só a desigualdade representa um obstáculo à democracia viva e ativa, mas o próprio conjunto de instituições representativas regulatórias operam contra a soberania e o poder popular ao criar uma distância entre o cidadão e a esfera de ação política (WOOD, 2006, p.179-189). Assim, experiência política vai ficando cada vez mais apartada dos setores populares, restrita a espaços institucionais (Congressos, Parlamentos, Câmaras) vistos como realmente legítimos, ordenados, controlados e invariavelmente mais seguros que os tradicionais espaços públicos como, praças, parques, ruas e bares. A forma como é construída a democracia representativa no capitalismo é o avesso do exercício do poder popular: promove a renúncia à participação política; esvazia a democracia de seu conteúdo social; aprofunda a alienação e a apatia; desvaloriza, enfim, a própria cidadania.

O impacto social gerado pelo imaginário de falta de alternativa e pelo apassivamento político foi também observado por Eric Hobsbawm em "Globalização, democracia e terrorismo" (2007). Ao olhar para o recente desenvolvimento das democracias liberais a partir da década de 1970, e mais amplamente para contexto de liberalização do mundo após a desagregação do bloco socialista, o historiador inglês explicita a relação entre o processo de avanço da mercantilização de serviços públicos essenciais -garantidores de inclusão - e o arrefecer das lutas políticas.

...desde a década de 1970, pelo retorno, por parte de políticos e ideólogos, a um laissezfaire ultra-radical, que critica o Estado e sustenta que seu papel tem de ser reduzido a qualquer preço. (...). Desde então, a substituição dos serviços públicos (e, aliás, também os serviços cooperativos) por serviços privados ou privatizados tem sido maciça. (...) O ideal da soberania do mercado não é um complemento à democracia liberal, e sim uma alternativa a ela. É, na verdade, uma alternativa a todos os tipos de política, pois nega a necessidade de decisões políticas, que são justamente aquelas relativas aos interesses comuns ou grupais que se distinguem da soma das escolhas, racionais ou não, dos indivíduos que buscam suas preferências pessoas. (...) A participação no mercado substitui a participação na política. O consumidor toma o lugar do cidadão (HOBSBAWM, 2007, p.105-106).

As últimas frases do autor revelam um lado muito particular da democracia liberal contemporânea: a identificação da democracia com livre mercado e capacidade de consumo. 
Tal associação, condizente com o princípio liberal de isolamento e proteção da esfera econômica da vida política, permite inclusive invocar a democracia em defesa da redução de direitos políticos e sociais para proteger a propriedade e o livre mercado.

É a partir desses questionamentos que procuramos desenvolver a reflexão acerca do aumento significativo dos crimes de ódio, a crescente naturalização da violência e da intolerância e a falta de políticas públicas enfáticas no combate a essas manifestações. $\mathrm{O}$ caráter alienante e apassivador da democracia liberal contemporânea deu origem a um ambiente que propicia e alimenta (porém não determina) a anestesia diante da desigualdade, de injustiças, da perda de direitos e da violência cotidiana. A democracia liberal contemporânea naturaliza a barbárie e reprime as escassas manifestações de insatisfação e descontentamento.

O recente avanço de manifestações de ódio e intolerância e os ataques contra a dignidade humana são sintomáticos de um meio social e de uma estrutura sócio-mental que permitem a sua naturalização, através do descaso e da indiferença derivados do individualismo exacerbado ou de explicações como casos isolados, excessões ou expressões marginais. Qualquer dessas alternativas contribui para a perpetuação desses atos e para nossa insensibilidade perante a vida. A batalha contra o avanço do ódio e da intolerância vai, portanto, muito além das lutas contra as discriminações, devendo caminhar no sentido do resgate de uma democracia ativa, militante e reflexiva, o que implica ir de encontro à lógica da reprodução social do capital.

\section{O avançar do ódio e da intolerância na Europa contemporânea}

Os dados apresentados pelos quadros e tabelas a seguir demonstram empiricamente o que muitos intelectuais vêm observando com preocupação já há algum tempo: o aumento da violência motivada pelo ódio e uma maior aceitação pública de grupos e partidos que difundem o ódio e a intolerância como caminhos para a solução dos problemas sociais na Europa. $^{2} \mathrm{O}$ primeiro quadro revela o crescimento da xenofobia na maioria dos países da Europa entre 1999 e 2008. Em alguns casos, como na Áustria [Österreich], Estônia [Estland], República Tcheca [Tschechien], Letônia [Letônia], Alemanha [Deutschland], Holanda

\footnotetext{
${ }^{2}$ Os dados foram produzidos a partir de pesquisas desenvolvidas pela European Union Agency for Fundamental Rights (FRA), agência criada em 2007 com o objetivo de prover as instituições da União Europeia (UE) e os Estados-membros com informações, dados e sugestões relevantes no tocante à garantia dos direitos fundamentais (civis, políticos, sociais e humanos) dos cidadãos e residentes da UE. O FRA veio substituir o European Monitoring Centre on Racism and Xenophobia, que funcionou com propósito análogo de 1998 a 2007, e em virtude de pressões sociais e políticas teve seu escopo de atuação alargado, de forma incluir discriminações de gênero, religião, sexualidade, político-ideológica e deficiências físicas e mentais.
} 
[Niederlande] e Rússia [Russland] esse crescimento é significativo, chegando praticamente dobrar o índice de xenofobia. O segundo, fruto de uma pesquisa de opinião feita entre 2007 e 2008 com imigrantes e descendentes de imigrantes residentes na Europa, mostra quais minorias estão mais sujeitas a discriminações, ataques e ameaças de agressão (física ou verbal) em cada país.

\section{Quadro 1: Xenofobia na Europa}

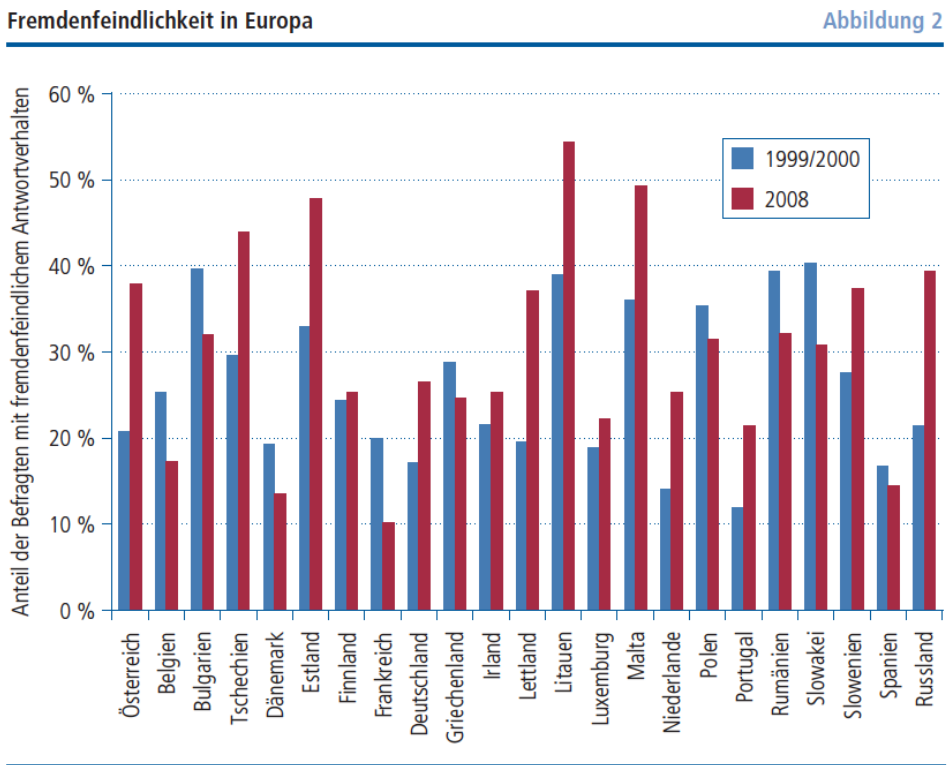

Quelle: Die Daten sind den Europäischen Wertestudien (EVS) 1999-2000 und 2008 entnommen:; http://zacat.gesis.org/webview/index.jpp?object=http://zacat.gesis.org/obj/fCatalog/Catalog5 (Zugriff 17.11.2011).

(MELTZER;SERAFIN, 2013, p.17)

Quadro 2: Crimes ódio étnico-racial na Europa: principais minorias atacadas

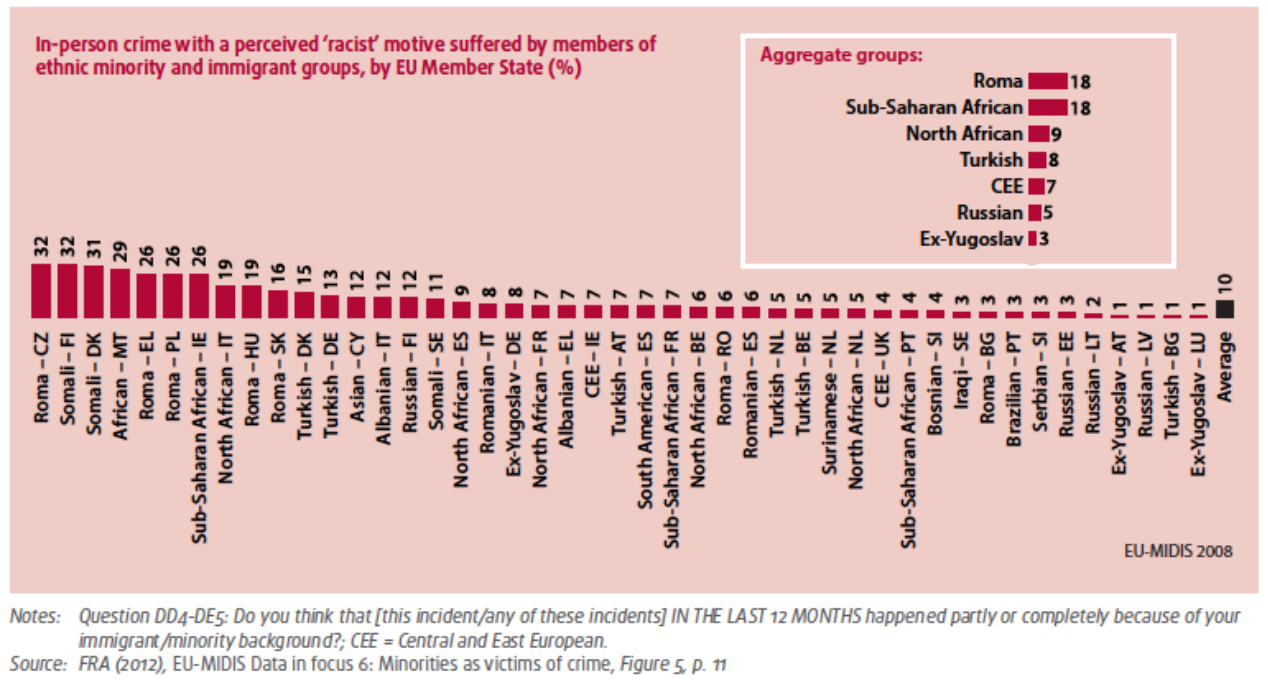

(FRA. Hate Crime in the European Union, 2012, p. 2)

Os resultados impressionam e preocupam, ainda mais quando levamos em conta a ressalva presente em quase todos os documentos, relatórios e estatísticas produzidos pela European Union Agency for Fundamental Rights (FRA), enfatizando o fato de muitos casos

Oficina do Historiador, Porto Alegre, EDIPUCRS, v. 9, n. 1, jan./jun. 2016, 
de discriminação e agressão não serem denunciados e, portanto, não contabilizados estatisticamente. Isso cria de imediato uma dificuldade na construção de um quadro realista da situação, mas também denota outras dimensões do problema que contribuem para seu agravamento, quais sejam: por um lado a falta de confiança da população nas agências de aplicação da lei e manutenção da ordem, por outro o sentimento de impunidade por parte dos perpetradores. Isso implica dizer que há uma crise de legitimidade das instituições da democracia liberal, um obstáculo de cunho político para o combate ao ódio e à intolerância.

$\mathrm{O}$ aumento da tendência de rechaço ao outro, visto como ameaça ou mesmo como um ser inferior, vem contribuindo para a popularização e para o consequente avanço eleitoral dos partidos de extrema-direita na Europa. Como podemos observar na tabela 1, partidos ultranacionalistas e fascistoides vêm crescendo em maior ou menor proporção em todos os países da Europa Ocidental, demonstrando o sucesso de suas estratégias de mobilização e organização política do ódio e da intolerância.

Tabela 1: Resultados eleitorais da direita radical (em \%) em eleições parlamentares nacionais na Europa ocidental desde 1980

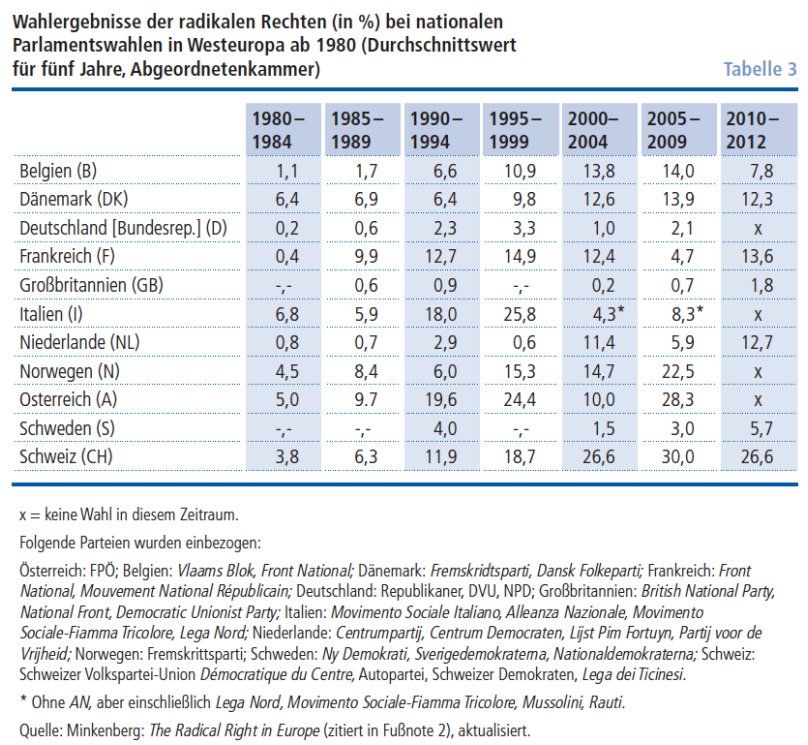

(MELTZER; SERAFIN, 2013, p.22) ${ }^{3}$

\footnotetext{
${ }^{3} \mathrm{X}=$ Não houve eleição no período

Os seguintes partidos foram incluídos: Austria: FPÖ; Bélgica: Vlaams Blok, Front national; Dinamarca: Fremskridtsparti, Dansk Folkparti; França: Front National, Mouvement National Républicain; Alemanha: Republikaner, DVU, NPD; Gran-Bretanha: British National Party, National Front, Democratic Unionist Party; Itália: Movimento Sociale Italiano, Alleanza Nazionale, Movimento Sociale-Fiamma Tricolore, Lega Nord; Holanda:Centrumpartij, Centrum Democraten, Lijst Pim Fortuyn, Partij voor de Vrijheid; Noruega: Fremskrittsparti; Suécia: Ny Demokrati, Sverigedemokraterna, Nationaldemokraterna; Suíça: Schweizer Volkspartei-Union Démocratique du Centre, Autopartei, Schweitzer Demokraten, Lega dai Ticinesi.

*Sem Alleanza Nazionale, porém incluindo Lega Nord, Movimento Sociale-Fiamma Tricolore, Mussolini, Rauti.
} 
Tal cenário não se configura na Europa Leste, onde, com exceção da Hungria, os partidos de extrema-direita parecem ter perdido terreno, pelo menos no campo político eleitoral. Uma análise crua dos dados poderia levar à constatação de uma aparente contradição, haja vista as informações trazidas pelo quadro da xenofobia e pela própria bibliografia especializada (KERSTEN; HANKEL, 2013. BUSTIKOVA, 2013). O que podemos aferir a partir de um olhar mais cuidadoso sobre os números expostos na tabela e a bibliografia é que os dados da tabela da Europa Leste revelam mais sobre as dificuldades de organização política desses partidos no Leste ou mesmo da opção pela luta fora da arena político-partidária, mais atuante na sociedade civil através de movimentos políticos de base.

Tabela 2: Resultados eleitorais da direita radical (em \%) em eleições parlamentares nacionais na Europa Leste desde 1990

\begin{tabular}{|c|c|c|c|c|c|}
\hline \multicolumn{5}{|c|}{$\begin{array}{l}\text { Wahlergebnisse der radikalen Rechten (in \%) bei nationalen } \\
\text { Parlamentswahlen in Ostmitteleuropa ab } 1990 \text { (Durchschnittswert für } 5 \text { Jahre, } \\
\text { Abgeordnetenkammern) }\end{array}$} & Tabelle 5 \\
\hline & $1990-1994$ & $1995-1999$ & $2000-2004$ & $2005-2009$ & $2010-2012$ \\
\hline Polen (PL) & 14,1 & $8,0^{*}$ & 18,1 & 10,4 & 0,0 \\
\hline Rumänien (RO) & 5,8 & 9,2 & 20,9 & 3,1 & 1,2 \\
\hline Slowakische Republik (SR) & k.D. & K.D. & 7,0 & 11,7 & 4,8 \\
\hline Slowenien (SV) & k.D. & k.D. & 4,4 & 5,4 & 1,8 \\
\hline Tschechische Republik (CZ) & $6,8^{* *}$ & 6,0 & 1,1 & -- & 1,1 \\
\hline Ungarn $(\mathrm{H})$ & 0,8 & 5,5 & 4,5 & 1,7 & 16,7 \\
\hline \multicolumn{6}{|c|}{ Folgende Parteien wurden einbezogen: } \\
\hline \multicolumn{6}{|c|}{$\begin{array}{l}\text { * Geschätzter Anteil von ZChNund KPN, die } 1997 \text { mit einer gemeinsamen Liste mit dem Wahlbündnis Solidarnosc } \\
\text { AWS antraten (Stimmenanteil 33,8\%) } \\
\text { ** Tschechischer Nationalrat }\end{array}$} \\
\hline
\end{tabular}

(MELTZER;SERAFIN, 2013, p. 28)

Análises contidas no paper apresentado por Kelly Shaw e Joseph Kibitlewski no encontro da European Community Studies Association em 2001, bem como na recente coletânea organizada por Von Mering e McCarthy (2013), afirmam que a violência motivada pelo ódio deve ser entendida a partir de uma abordagem totalizante, estando ligada tanto à questões culturais e religiosas como econômicas. "Tempos de incerteza financeira e econômica geralmente caminham de mãos dadas com a radicalização política, como defendem os que traçam paralelos entre os acontecimentos presentes e aqueles do fim dos anos 1920 (Von MERING; McCARTY, 2013, p.1). " Segundo pesquisas do Eurobarometer 53, publicado em 2000, questões como o aumento do desemprego e da criminalidade, queda

\footnotetext{
${ }^{4}$ Os seguintes partidos foram incluídos: Polônia KPN, ZChN, LPR, Samoobrona; Romênia: PUNR, PRM; Eslováquia: SNS; Eslovênia: SNS; República Tcheca: SPR-RSC, Partido dos Trabalhadores; Hungria: MIÉP, Jobbik.

* Parcela estimada do ZChN e KPN, que competiram eleitoralmente em aliança com Solidarnosc AWS em 1997 (votos: $33 \%$ )

** Conselho Nacional Tcheco
} 
dos níveis educacionais e a crescente percepção de abuso dos sistemas de bem-estar por minorias constituem indícios para explicar o crescimento do racismo e da violência motivada pelo ódio na passagem do século XX para o XXI.

Nesse sentido, a interação complexa de elementos políticos (crise de legitimidade), econômicos (crise econômica, desemprego), culturais e religiosos (preconceitos enraizados) ajuda a entender o processo de construção do chamado "bode expiatório", responsabilizando um terceiro elemento, geralmente uma minoria nacional ou estrangeira, pelos males sociais experimentados por uma sociedade. Contextos de crise ou de transformações sociais paradigmáticas, como as vivenciadas pelo Leste Europeu durante a desagregação do bloco socialista, configuram um terreno propício ao fortalecimento de "bodes expiatórios" e ao aumento dos atos de violência motivada pelo ódio por parte de grupos sociais fragilizados.

A União Europeia e os Estados-Membros vêm procurando desde os anos 2000 lidar com o desafio da violência e dos crimes motivados pelo ódio através de estratégias similares às adotadas pelos EUA. Os EUA iniciaram o combate ao ódio e à intolerância na década de 1970, com o monitoramento de grupos de ódio pelo FBI, a implementação de mecanismos legais de coleta obrigatória de dados estatísticos (Hate Crime Statistics Act of 1990) e agravamento penal quando observado motivo de ódio (Violent Crime Control and Law Enforcement Act of 1994). Na UE os dados tanto institucionais quanto produzidos por ONGs são mais escassos entre os anos 1970 e 1980, mas pode-se notar que as estratégias desenvolvidas se assemelham bastante às norte-americanas, buscando atacar o problema em direção muito similar, fazendo uso basicamente de mecanismos legais e pedagógicos. Como veremos a seguir, as principais ações são de tipo repressivo-condenatórias, consistindo em proibições e amparo legal, e pedagógico-educacional, procurando construir consciência e estimular a valorização da diversidade através de projetos educacionais, informativos e de treinamento de agentes da polícia e do judiciário.

Uma particularidade a ser observada quando tratamos de investigar qualquer problemática referente à UE é justamente o fato de ser uma união de Estados, um bloco político, econômico e cultural, mas que preserva ainda os Estados nacionais como agentes autônomos e soberanos. Isso importa especialmente porque muitas medidas tomadas pela UE são diretrizes, ou seja, têm caráter sugestivo, mas não deliberativo. Somente em casos muito extremos a UE tem permissão de realizar um julgamento, conduzido pelo European Court of Human Rights (ECtHR). No caso de normas coletivamente acordadas e de aplicação mandatória é reservada aos Estados a autonomia para decidir como melhor implementar. Toda 
a documentação aqui trabalhada guarda essa especificidade, criando muitas vezes entraves para o desenvolvimento de um plano de ação conjunto de combate ao ódio.

Esse é o caso do sistema de coleta de dados estatísticos. Os mecanismos de coleta de e publicação de dados variam enormemente entre os 27 Estados-membros da UE. Alguns países coletam dados, mas publicam parcialmente; outros coletam e publicam dados referentes somente à determinadas minorias; alguns incluem dados sobre o perfil do perpetrador, julgamento e condenação, outros não; alguns contêm legislação relativa ao discurso e incitação do ódio, outros não; alguns coletam, publicam e incluem uma análise dos dados. Apenas 8 Estados coletam dados relativos a crimes motivados por ódio à orientação sexual (ou percepção de orientação sexual); apenas 4 publicam dados de crimes cometidos contra ciganos (ou percepção de pertencimento étnico)! Isso dificulta a comparação da situação do ódio e as estratégias de contenção do problema nos países, bem como a formação de um quadro do ódio e da intolerância na UE, a construção de um sistema europeu de monitoramento e a implementação de ações e projetos comuns.

Nos EUA, o combate aos crimes de ódio foi especialmente motivado pelo movimento dos direitos civis e de afirmação de outras minorias nos anos 1960. Na Europa, diferentemente, essa batalha veio de mãos dadas com o debate em torno dos direitos humanos. Não à toa, as instituições, agências e legislações da UE dedicadas ao combate ao ódio e à intolerância são organismos voltados para garantia e proteção dos direitos humanos.

A primeira iniciativa nesse sentido foi a criação em 1997 do European Monitoring Centre on Racism and Xenophobia (EUMC) pelo Council of Europe, organização intergovernamental, criada em 1949 com objetivo de promover a democracia e os direitos humanos. A proposta do EUMC era estudar extensão das manifestações de racismo, xenofobia e anti-semitismo na UE e sugerir aos países-membros algumas medidas para enfrentar o problema, como, por exemplo, o aumento de sentença caso observado motivo de ódio racial (SHAW; KIBITLEWSKI, 2001, p. 7-8).

A iniciativa pioneira do EUMC foi fortalecida pelo Tratado de Amsterdam (1997), garantindo através do artigo 13 uma base legal para o combate à discriminação não apenas racial, mas igualmente de outras minorias. “...o Conselho [European Council], agindo unanimemente em favor de uma proposta da Comissão [European Commision] e, após consultar o Parlamento Europeu, pode tomar medidas adequadas para combater a discriminação contra sexo, origem étnica ou racial, religião ou crença, deficiência, idade ou orientação sexual (Tratado de Amsterdam, 1997. Artigo 13). ’ 
As diretivas do Tratado de Amsterdam, alargando o escopo de proteção civil e humanitária a outras minorias tornou-se a tônica de todos os tratados, relatórios produzidos por agências e instituições da UE e dispositvos legais aprovados daí em diante. O documento mais importante nesse sentido é a Charter of Fundamental Rights aprovada no ano 2000 pelo Parlamento Europeu, o Council of Ministers e pela European Commission, corpo executivo da UE responsável por propor legislações, implementar decisões e fazer valer as diretivas dos tratados. A Carta contém um conjunto de princípios, regulamentos, direitos políticos, sociais e econômicos que devem ser aplicados em todas as Instituições da UE e assegurados por todos os Estados-membros. O artigo 21 da Carta proíbe terminantemente qualquer tipo de discriminação.

Qualquer discriminação de qualquer tipo, como sexo, raça, cor, origem social ou étnica, traços genéticos, língua, religião ou ideia política ou qualquer tipo de opinião, associação ou minoria nacional, propriedade, nascimento, deficiência, idade ou orientação sexual deverá ser proibida (Charter of Fundamental Rights, Article 21. 2000).

O artigo 21 da Carta vem servindo de base argumentativa em muitos casos conduzidos pelo European Court of Human Rights (ECtHR). A partir dele, a ECtHR determinou em diversos casos da última década que os Estados-membros devem procurar identificar, declarar publicamente a motivação de ódio, punir e condenar publicamente qualquer crime motivado pelo preconceito [bias motivation]. Negligenciar a discriminação como motivo seria considerado uma violação às determinações do artigo 21 da Carta e também ao artigo 14 da European Convention of Human Rights (1953). O artigo 21 embasa ainda a Framework Decision on Racism and Xenophobia (2008), primeira tentativa de construção de uma abordagem comum de lei criminal na UE e os países teriam até 2010 para implementar a diretiva.

Quanto aos programas educacionais, os desafios são ainda maiores justamente por serem de âmbito nacional, não se conseguindo organizar e aprovar ainda algo no sentido mais amplo da UE. Os projetos de cunho pedagógico visam combater o problema a curto e longo prazo, pois o processo educativo vai além da repressão e condenação de ações e discursos discriminatórios, alcançando gerações futuras por meio da conscientização. Além disso, esse tipo de estratégia entende que uma particularidade dos crimes de ódio é que esses ultrapassam o acontecimento específico entre vítima e perpetrador, promovendo medo e insegurança em toda uma comunidade, grupo social ou minoria. A ação perpetrada emana sempre uma 
mensagem de ódio que humilha, fragiliza e ameaça um conjunto muito maior de pessoas, além de carregar o potencial de incitar seguidores.

Alguns projetos tiveram sucesso e serviram de inspiração para outras experiências. $\mathrm{O}$ projeto Athena, implementado em Londres pela Scotland Yard em 1998 é um exemplo de programa de treinamento para policiais e detetives, que busca preparar melhor esses profissionais, estimulando a tolerância, a aceitação da diversidade e a cooperação com as comunidades formadas por minorias. A experiência inglesa inspirou e fundamentou o manual de treinamento para policiais produzido pela FRA em 2013 com sugestões para o treinamento de profissionais aos Estados-Membros (Fundamental rights-based police training: a manual for police trainers, 2013).

$\mathrm{Na}$ Alemanha é onde se encontra o maior número de programas pedagógicos de celebração da diversidade. Um dos mais relevantes é o Child and Youth Plan, que busca promover a diversidade e uma educação multicultural. Segundo o Report on Racism and Xenophobia in the Member States of the EU, publicado pela FRA em 2007, os crimes motivados pelo ódio racial são frequentes na Alemanha, crescendo numa ordem de $14 \%$ ao ano. Isso explica a preocupação desse país com o investimento em educação multicultural. Contudo, o debate e as estratégias civis contra ódio vêm gerando pouco impacto jurídico. Não existe na Alemanha uma legislação contra crimes de ódio, nem mesmo na forma de emenda constitucional, como nos EUA e na Inglaterra. O discurso de ódio é criminalizado, mas a motivação não é necessariamente levada em conta no momento da definição do crime ou na execução da sentença. Fica a critério do juiz em causa considerar o motivo de ódio no momento da aplicação da sentença e determinação da pena (COESTER, 2008).

ONGs nacionais e internacionais têm contribuído no estímulo à conscientização e aceitação da diferença. Poderíamos citar os projetos desenvolvidos por Human Rights Watch, Human Rights First, Anistia Internacional, Stop Hate UK e Hope not Hate.

Tais estratégias de caráter repressivo-condenatórias e pedagógico-culturais são obviamente importantes e o fato de tamanha investida em tempo relativamente curto revelam conquistas significativas com respeito à luta contra a discriminação e o preconceito. Contudo, os dados extraídos da FRA mostram que, apesar dos esforços, os números continuam a subir na maioria dos países. Poderíamos imputar tal movimento a um aumento das denúncias. Todavia, a documentação reforça justamente essa ressalva, a do desafio em estimular as denúncias. As análises desenvolvidas na seção anterior sobre o caráter paradoxal, excludente e alienante da democracia liberal contemporânea só vêm fortalecer nossa tese da crise de legitimidade, reafirmando que o desafio político e social está longe de ser resolvido. Os meios

Oficina do Historiador, Porto Alegre, EDIPUCRS, v. 9, n. 1, jan./jun. 2016, 
utilizados até o momento para o combate do ódio e da intolerância negligenciam tanto à dimensão econômico-social quanto à político-social. Apostam e atuam unicamente na esfera legal-institucional e cultural-educacional, pois esses são espaços seguros, que não comprometem necessariamente o cerne das relações de poder e dominação. São os espaços de luta possíveis dentro da ordem estabelecida; a margem de conquista na "queda de braço" entre os detentores do poder e os setores subordinados, onde se encontram grande parte das minorias perseguidas; é, enfim, o limite da democracia dentro de uma sociedade burguesa. Atentar para o fundamento político-social e material do ódio e lutar contra ele implicaria o desenvolvimento de estratégias de combate à desigualdade e à alienação, que sustentam as democracias liberais contemporâneas. Os intolerados, odiados e subordinados do XXI têm à sua frente o grande desafio de retomar essas lutas em particular para afirmar o direito à vida, à política, ao acesso aos bens públicos e à dignidade humana.

\section{Referências Bibliográficas}

BUSTILOVA, Lenka. Welfare chauvinism, ethnic heterogeneity and conditions for the electoral breakthrough of radical right parties: evidence form Eastern Europe. In: VON MERING, Sabine; McCARTY, Timothy. Right-Wing Radicalism Today: perspectives from Europe and the US. New York: Routledge, 2013.

CMIEL, Kenneth. The recent history of human rights. American Historical Review. February, 2004.

COESTER, Marc. Das Konzept der Hate Crimes aus den USA unter besonderer Berücksichtigung des Rechtsextremismus in Deutschland. Peter Lang: Berlin, 2008.

HOBSBAWM, Eric. Globalização, democracia e terrorismo. São Paulo: Cia das letras, 2007. HOCHSCHILD, Adam. King Leopold's Ghost: a story of greed, terror and heroism in colonial Africa. New York: Mariner books, 1998.

HUNT, Lynn. A invenção dos direitos humanos: uma história. São Paulo: Cia das Letras, 2009.

ISHAY, Micheline. The history of human rights: from ancient times to the globalization era. Berkeley: University of California Press, 2004.

LAUREN, Paul Gordon. The evolution of international human rights: visions seen. Philadelphia: University of Pennsylvania Press, 2003.

LOSURDO, Domenico. Democracia ou bonapartismo: triunfo e decadência do sufrágio universal. Rio de Janeiro: EdUFRJ, 2004.

KERSTEN, Joachim; HANKEL, Natalia. A comparative look at right-wing extremism, antisemitism and xenophobic hate crimes in Poland, Ukraine and Russia. In: VON MERING, Sabine; McCARTY, Timothy. Right-Wing Radicalism Today: perspectives from Europe and the US. New York: Routledge, 2013.

MARSHALL, Thomas Humphrey. Cidadania, classe social e status. Rio de Janeiro: Zahar, 1967.

MELZER, Ralf; SERAFIN, Sebastian. Recht-extremismus in Europa: Länderanalysen, Gegenstrategien und arbeitsmarktorientierte Ausstigsarbeit. Frankfurt am Main: Verlaghaus Zarbock, 2013. 
MONDAINI, Marco. Revolução inglesa: o respeito ao direito dos indivíduos. In: PINSKY, Jaime; PINSKY, Carla Bassanezi. História da Cidadania. São Paulo: Contexto, 2015.

PENDAS, Devin. Toward a new history? On recent historiography of human rights. Contemporary European History. 21, I, 2012. p.95-111.

POWER, Samantha. A problem from hell: America and the age of genocide. New York: Basic Books, 2002.

SHAW, Kelly; KIBITLEWSKI, Joseph. Hate, hate groups and hate crimes: fighting xenophobia in the European Union. European Community Studies Association. 31 May - 2 June, 2001.

VASAK, Karal. Les Dimensions internationales des Droits de l'Homme. Paris: UNESCO, 1978.

VIEIRA, Liszt. Os argonautas da cidadania. Rio de Janeiro: Record, 2001.

VON MERING, Sabine; McCARTY, Timothy. Right-Wing Radicalism Today: perspectives from Europe and the US. New York: Routledge, 2013.

WOOD, Ellen. Democracia contra capitalismo: a renovação do materialismo histórico. São Paulo: Boitempo, 2006.

\section{Documentação}

Charter of Fundamental Rights, 2000. Disponível em: http://www.europarl.europa.eu/charter/pdf/text_en.pdf. Acesso em: Agosto de 2014.

Eurobarometer 53, 2000.2 Disponível em:
data.europa.eu/en/data/dataset/S1407_53_0_ST53. Acesso em: Outubro de 2014.

FRA. Hate Crime in the European Union, 2012. Disponível em: http://fra.europa.eu/en Acesso em: Outubro 2014.

FRA. Making Hate crimes visible in the European Union, 2012. Disponível em: http://fra.europa.eu/en Acesso em: Outubro 2014.

FRA. Fundamental Rights Conference. Combating Hate Crime in the EU, 2013. Disponível em: http://fra.europa.eu/en Acesso em: Outubro 2014.

Tratado de Amsterdã, 1997. Disponível em: http://europa.eu/eu-law/decisionmaking/treaties/pdf/treaty_of_amsterdam/treaty_of_amsterdam_pt.pdf . Acesso em: Agosto de 2014.

ARTIGO ENVIADO EM: 18/01/2016

ACEITO PARA PUBLICAÇÃO EM: 03/06/2016

Oficina do Historiador, Porto Alegre, EDIPUCRS, v. 9, n. 1, jan./jun. 2016, 